\title{
The acute transcriptome response of the midbrain/diencephalon to injury in the adult mummichog (Fundulus heteroclitus)
}

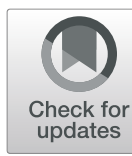

\author{
Eleanor C. Bisese', Chandler M. Ciuba', Amelia L. Davidson', Akanksha Kaushik', Sabrina M. Mullen', \\ Jeremy L. Barth², E. Starr Hazard ${ }^{3}$, Robert C. Wilson ${ }^{4}$, Gary Hardiman ${ }^{5,6}$ and David M. Hollis ${ }^{1 *}$ (D
}

\begin{abstract}
Adult fish produce new cells throughout their central nervous system during the course of their lives and maintain a tremendous capacity to repair damaged neural tissue. Much of the focus on understanding brain repair and regeneration in adult fish has been directed at regions of the brainstem and forebrain; however, the mesencephalon (midbrain) and diencephalon have received little attention. We sought to examine differential gene expression in the midbrain/diencephalon in response to injury in the adult fish using RNA-seq. Using the mummichog (Fundulus heteroclitus), we administered a mechanical lesion to the midbrain/diencephalon and examined differentially expressed genes (DEGs) at an acute recovery time of $1 \mathrm{~h}$ post-injury. Comparisons of whole transcriptomes derived from isolated RNA of intact and injured midbrain/diencephalic tissue identified 404 DEGs with the vast majority being upregulated. Using GPCR, we validated the upregulation of DEGs pim-2-like, syndecan4-like, and cd83. Based on genes both familiar and novel regarding the adult brain response to injury, these data provide an extensive molecular profile giving insight into a range of cellular processes involved in the injury response of a brain regenerative-capable vertebrate.
\end{abstract}

Keywords: Brain injury, Acute, Mummichog, Transcriptome, Midbrain, Diencephalon, pim-2-like, syndecan-4-like, cd83

\section{Background}

Adult fish possess tremendous neural regeneration capabilities. While the adult mammalian brain is severely limited in its ability to self-repair, fish exhibit a tremendous capacity for neural regeneration and thus, a remarkable ability to recover from brain injury as they readily replace damaged cells due to their ability to constitutively proliferate new cells [1]. Thus, due to their having exceptional potential to regenerate neuronal tissue post-injury, fish are an excellent model for adult brain regeneration-competency [2]. Factors responsible for the differences in adult brain cell proliferation, and subsequent neurogenesis, between species of different vertebrate classes remain largely unknown. Therefore, elucidating the genes involved in the adult fish brain reparative process has

\footnotetext{
*Correspondence: david.hollis@furman.edu

'Department of Biology, Furman University, 3300 Poinsett Highway,

Greenville, SC 29613, USA

Full list of author information is available at the end of the article
}

the potential to better understand the molecular mechanisms underlying these discrepancies.

Cell proliferation and neurogenesis are abundant throughout the adult fish brain [3]. Much of the focus on adult fish brain repair has been directed at neuronal tissue of the forebrain and brainstem, however, the mesencephalon (midbrain) and diencephalon have received relatively little experimental study with regard to reparative neurogenesis relative to the other regions [4]. Studies using genomic approaches, specifically RNA-seq, to assay the molecular signals associated with brain regeneration and neurogenesis in the fish brain are beginning to uncover significant genes and pathways [5]. To further this end, we used RNA-seq to examine the acute response of the midbrain/diencephalon of the mummichog (Fundulus heteroclitus). While the zebrafish (Danio rerio) has been widely used to examine molecular mechanisms of pathological conditions such as brain repair, 


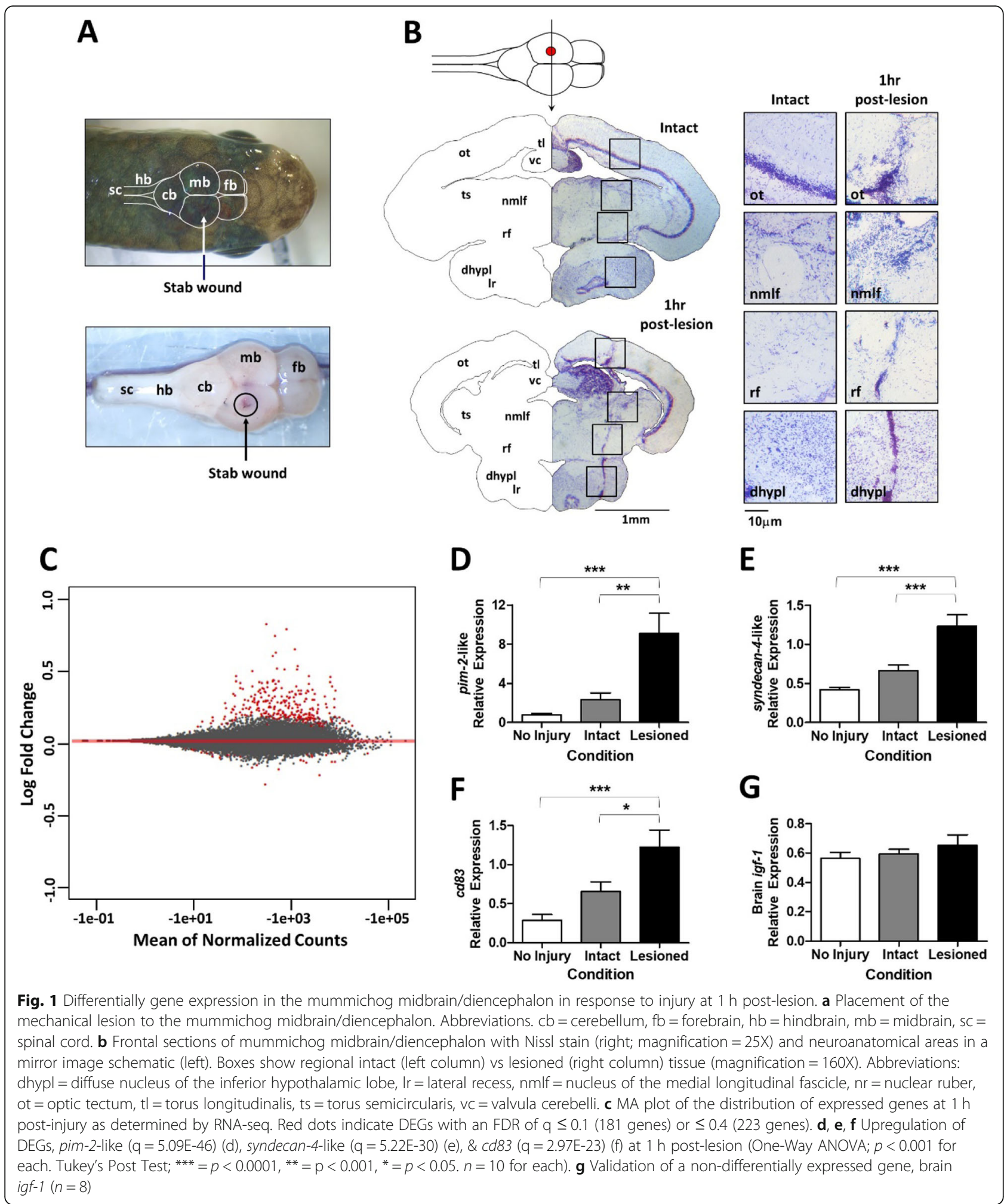

alternative fish species, such as the mummichog, allow for potential novel gene function discovery due to differential subfunctionalization of genes between the different fish lineages [6].

\section{Materials and methods}

A detailed description of all experimental methods including animal care, surgical process, Nissl staining, RNA-seq, and qPCR can be found in Additional file 1. A 
mechanical lesion was administered to the midbrain and underlying hypothalamic diencephalon of anesthetized adult mummichogs. After injury, fish were given an acute recovery time of $1 \mathrm{~h}$ prior to sacrifice. To ensure lesion accuracy, Nissl stain was performed on $20 \mu \mathrm{m}$ thick frontal sections of the midbrain/diencephalon to visualize the injury using light microscopy.

For RNA-seq, the total RNA was isolated from the lesioned side of the midbrain/diencephalon as well from the contralateral, intact side of the midbrain/diencephalon of ten fish. The total RNA from each sample was used to prepare RNA-seq libraries which were clustered at concentrations to ensure at least 50 million reads per sample. Differential gene expression was inferred using DESeq2 [7]. Transcript counts from DESeq2 analysis were ranked according to adjusted $p$-value (q). The false discovery rate (FDR) was set at both $\mathrm{q} \leq 0.1$ or $<0.4$ on the premise that the lower threshold was appropriately very stringent for identifying high-probability DEGs, while the higher threshold was more permissive and thus, avoided the loss of data via false negatives and would therefore aid discovery in the downstream functional analyses by providing a larger input gene list as we have demonstrated previously $[8,9]$. The gene set identified by $\mathrm{q} \leq 0.4$ was then analyzed with the ToppFun tool [10] to find enriched GO terms and pathways. The systems level output (GO and Pathway) was itself subjected to FDR testing thereby adding rigor to the data analysis [see 8,9$]$.

To validate DEGs, qPCR was performed (on eight to ten fish distinct from the RNA-seq assay) utilizing genespecific primers (see Additional file 1: Table S1). Primers were designed for three DEGs of novel functional interest regarding the fish brain response to injury that showed high differential expression, which included pim-2-like, syndecan-4-like and cd83 molecule (cd83). In addition, for qPCR quality control, primers were designed for a gene of functional interest, igf-1 (insulin-like growth factor 1), to validate its lack of differential expression. Gene expression was normalized to elongation factor 1 alpha (efla) using primers designed in previous work [11]. Further, to determine if a whole midbrain/diencephalon gene expression response was elicited, midbrain/diencephalic tissue from ten fish receiving no injury was also included.

\section{Results}

Due to the relatively flattened head of the mummichog, it was ideal for the dorsal application of a mechanical lesion to the midbrain/diencephalon (Fig. 1a). Nissl stain confirmed that the lesion traversed the midbrain optic tectum and tegmental regions and into the underlying hypothalamic tissue of the diencephalon (Fig. 1b). Genes differentially expressed between the lesioned and contralateral intact midbrain/diencephalon tissue were identified using FDR-adjusted $p$-value cutoffs of $\mathrm{q}>0.1$ and 0.4 , respectively. In total, 404 DEGs were identified as differentially expressed with 181 DEGs meeting the FDR cutoff of $\mathrm{q} \leq 0.1$ (Additional file 2: Table S2). Most differential expression indicated gene upregulation (Fig. 1c), which accounted for nearly $80 \%$ of all DEGs and of those with FDRs of $\mathrm{q} \leq 0.1$, $90 \%$ were upregulated. Functional annotation of genes by GO analysis [see 10] revealed a broad range of biological processes indicating a strong influence over cell death and differentiation (see Additional file 2: Table S3).

From the qPCR studies (Additional file 2: Table S4), we validated the differential expression of two genes not previously identified in the fish brain response to injury, which included pim-2-like (Fig. 1d) and syndecan-4-like (Fig. 1e), both of which are associated with cell proliferation $[12,13]$. Also validated was $c d 83$ (Fig. 1f), which is associated as a regulator of activation in immune cells [14]. However, $c d 83$ was recently found in neuronal cells, including high expression levels in both the midbrain and hypothalamus indicating possible distinct neural function [15]. Finally, the lack of igf- 1 differential expression was also validated (Fig. 1g). The use of the mummichog midbrain/diencephalon as a novel model for the brain response to injury demonstrates its potential to identify genes yet to be discovered with putative roles in the brain reparative processes in regenerative-capable vertebrates.

\section{Supplementary information}

Supplementary information accompanies this paper at https://doi.org/10. 1186/s13041-019-0542-4.

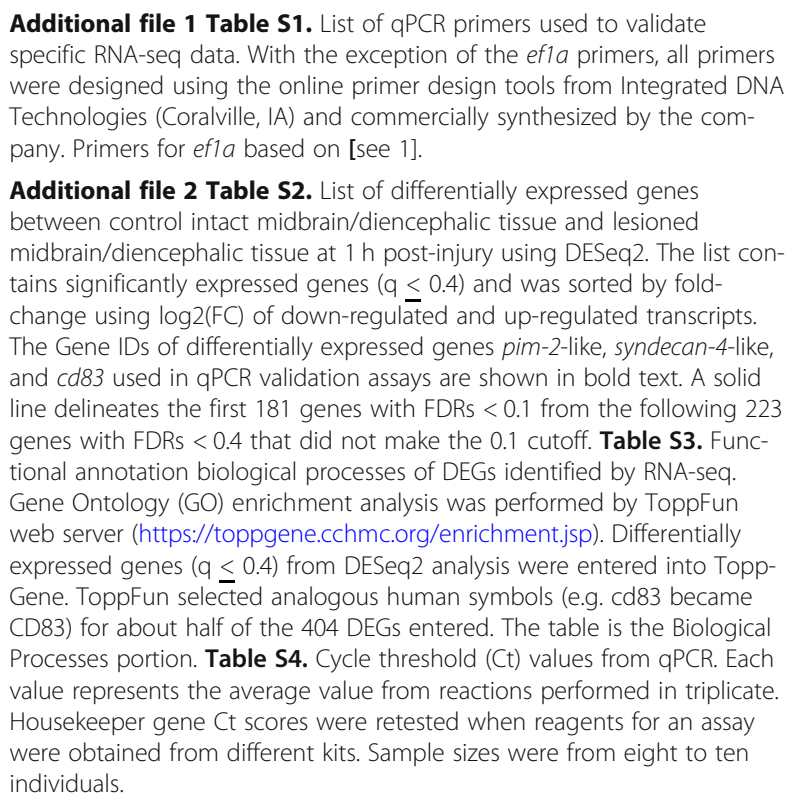

Additional file $\mathbf{2}$ Table S2. List of differentially expressed genes between control intact midbrain/diencephalic tissue and lesioned midbrain/diencephalic tissue at $1 \mathrm{~h}$ post-injury using DESeq2. The list contains significantly expressed genes $(q \leq 0.4)$ and was sorted by foldchange using $\log 2(\mathrm{FC})$ of down-regulated and up-regulated transcripts. The Gene IDs of differentially expressed genes pim-2-like, syndecan-4-like, and $c d 83$ used in GPCR validation assays are shown in bold text. A solid line delineates the first 181 genes with FDRs $<0.1$ from the following 223 genes with FDRs $<0.4$ that did not make the 0.1 cutoff. Table S3. Functional annotation biological processes of DEGs identified by RNA-seq. Gene Ontology (GO) enrichment analysis was performed by ToppFun web server (https://toppgene.cchmc.org/enrichment.jsp). Differentially expressed genes $(q<0.4)$ from DESeq2 analysis were entered into ToppGene. ToppFun selected analogous human symbols (e.g. cd83 became CD83) for about half of the 404 DEGs entered. The table is the Biological Processes portion. Table S4. Cycle threshold (Ct) values from qPCR. Each value represents the average value from reactions performed in triplicate. Housekeeper gene Ct scores were retested when reagents for an assay were obtained from different kits. Sample sizes were from eight to ten individuals.

\section{Abbreviations}

cd83: Cluster of differentiation 83; DEGs: Differentially expressed genes; ef1a: Elongation factor 1 alpha; GO: Gene ontology; igf-1: Insulin-like growth factor 1; pim-2: Proviral integration site for moloney murine leukemia virus, 
isoform 2; q: Adjusted p value; qPCR: Quantitative polymerase chain reaction; RNA-seq: RNA sequencing

\section{Acknowledgments}

Special thanks to Tergel Erdenetsogt, Carter Jardon, Jason Rawlings and John Wheeler of Furman University and Aquatic Research Organisms, Inc., of New Hampshire.

\section{Authors' contributions}

$\mathrm{DMH}$ and JLB conceived and designed the study. ALD, AK and DMH performed the mechanical lesions and histology. GH provided oversight for the RNA-seq experimentation. RCW performed RNA-seq. GH and ESH performed RNA-seq analysis. ESH performed GO analysis. CMC, ALD, and AK prepared tissue RNA samples. ECB, CMC, ALD, AK and SMM conducted experimental qPCR. DMH, GH, JLB, ESH, and RCW wrote and revised the manuscript. All authors read and approved the final manuscript.

\section{Funding}

This work was supported by INBRE award \#P20GM103499 to South Carolina from the National Institute of General Medical Sciences, National Institutes of Health. Additional support by the Furman Research \& Professional Growth (RPG) Award, and The Furman Advantage (TFA). GH acknowledges support from 1U01DA045300-01A1 and SC-EPSCoR. RCW acknowledges support from the Genomics Shared Resource, Hollings Cancer Center, Medical University of South Carolina.

\section{Availability of data and materials}

The RNA-seq data sets generated were deposited and are available at the NCBI Sequencing Read Archive database (Accession: GSE137451).

\section{Ethics approva}

The Furman University Institutional Animal Care and Use Committee (IACUC) approved the use of animals or their tissues in the study (IACUC protocol \# 01-19-06).

\section{Consent for publication}

Not applicable.

\section{Competing interests}

The authors declare that they have no competing interest.

\section{Author details}

${ }^{1}$ Department of Biology, Furman University, 3300 Poinsett Highway, Greenville, SC 29613, USA. ²Department of Regenerative Medicine \& Cell Biology, Medical University of South Carolina, 171 Ashley Avenue, Charleston, SC 29425, USA. ${ }^{3}$ Computational Biology Resource Center, Medical University of South Carolina, 171 Ashley Avenue, Charleston, SC 29425, USA. ${ }^{4}$ Pathology and Laboratory Medicine, Medical University of South Carolina, 171 Ashley Avenue, Charleston, SC 29425, USA. ${ }^{5}$ Department of Medicine, Medical University of South Carolina, 171 Ashley Avenue, Charleston, SC 29425, USA. ${ }^{6}$ School of Biological Sciences \& Institute for Global Food Security, Queen's University Belfast, Belfast, Northern Ireland BT9 5DL, UK.

Received: 1 October 2019 Accepted: 23 December 2019

Published online: 30 December 2019

\section{References}

1. Zupanc GK, Sîrbulescu RF. Adult neurogenesis and neuronal regeneration in the central nervous system of teleost fish. Eur J Neurosci. 2011;34(6):917-29.

2. Eriksson PS. Neurogenesis and its implications for regeneration in the adult brain. J Rehabil Med. 2003;35(41 Suppl):17-9.

3. Grandel H, Kaslin J, Ganz J, Wenzel I, Brand M. Neural stem cells and neurogenesis in the adult zebrafish brain: origin, proliferation dynamics, migration and cell fate. Dev Biol. 2006;295(1):263-77.

4. Alunni A, Bally-Cuif L. A comparative view of regenerative neurogenesis in vertebrates. Development. 2016;143(5):741-53.

5. Maheras AL, Dix B, Carmo OMS, Young AE, Gill VN, Sun JL, Booker AR, Thomason HA, Ibrahim AE, Stanislaw L, Dallego JC, Ngo CN, Chen A, Fortini BK, Spence RD. Genetic pathways of neuroregeneration in a novel mild traumatic brain injury model in adult zebrafish. eNeuro. 2018:5(1). ENEURO): 0208-17. https://doi.org/10.1523/ENEURO.0208-17.2017.
6. Schartl M. Beyond the zebrafish: diverse fish species for modeling human disease. Dis Model Mech. 2014;7(2):181-92.

7. Love Ml, Huber W, Anders S. Moderated estimation of fold change and dispersion for RNA-seq data with DESeq2. Genome Biol. 2014;15(12):550.

8. Huff M, da Silveira WA, Carnevali O, Renaud L, Hardiman G. Systems analysis of the liver Transcriptome in adult male Zebrafish exposed to the plasticizer (2- Ethylhexyl) phthalate (DEHP). Sci Rep. 2018;8(1):2118. https:/doi.org/10.1038/s41598-018-20266-8.

9. Hardiman G, Savage SJ, Hazard ES, Wilson RC, Courtney SM, Smith MT, Hollis BW, Halbert CH, Gattoni-Celli S. Systems analysis of the prostate transcriptome in African-American men compared with European-American men. Pharmacogenomics. 2016;17(10):1129-43.

10. Chen J, Bardes EE, Aronow BJ, Jegga AG. ToppGene Suite for gene list enrichment analysis and candidate gene prioritization. Nucleic Acids Res. 2009;37(Web Server issue):W305-11. https://doi.org/10.1093/nar/gkp427.

11. Scott GR, Richards JG, Forbush B, Isenring P, Schulte PM. 2004. Changes in gene expression in gills of the euryhaline killifish Fundulus heteroclitus after abrupt salinity transfer. Am J Physiol Cell Physiol. 2004;287(2):C300-9.

12. Narlik-Grassow M, Blanco-Aparicio C, Cecilia Y, Peregrina S, Serelde BG, Munoz-Galvan S, Canamero M, Carnero A. Essential role of PIM kinases in sarcoma growth and bone invasion. Carcinogenesis. 2012;33:1479-86.

13. Landry R, Rioux $V$, Bensadoun A. Characterization of syndecan-4 expression in 3T3-F442A mouse adipocytes: link between syndecan-4 induction and cell proliferation. Cell Growth Differ. 2001;12(10):497-504.

14. Breloer M, Fleischer B. CD83 regulates lymphocyte maturation, activation and homeostasis. Trends Immunol. 2008;29(4):186-94.

15. Glezer I, Bittencourt JC, Rivest S. Neuronal expression of $\mathrm{Cd} 36, \mathrm{Cd} 44$, and Cd83 antigen transcripts maps to distinct and specific murine brain circuits. J Comp Neurol. 2009;517(6):906-24.

\section{Publisher's Note}

Springer Nature remains neutral with regard to jurisdictional claims in published maps and institutional affiliations.

\section{Ready to submit your research? Choose BMC and benefit from:}

- fast, convenient online submission

- thorough peer review by experienced researchers in your field

- rapid publication on acceptance

- support for research data, including large and complex data types

- gold Open Access which fosters wider collaboration and increased citations

- maximum visibility for your research: over $100 \mathrm{M}$ website views per year

At $\mathrm{BMC}$, research is always in progress.

Learn more biomedcentral.com/submissions 